\title{
An event of underground predation on a wintering caudate amphibian by a carabid beetle
}

\author{
Rafał Bernard \& Juliusz Samoląg
}

Bernard, R. \& Samoląg, J. 2014: An event of underground predation on a wintering caudate amphibian by a carabid beetle. — Entomol. Fennica 25: 157-160.

Pterostichus niger (Coleoptera: Carabidae) preying on Lissotriton vulgaris (Caudata: Salamandridae) in complete darkness and fairly low ambient temperatures was recorded in mid-winter in the underground fortifications near Strzaliny, NW Poland, confirming the occurrence of the predation on small caudate amphibians by carabid beetles in natural conditions. The long but successful predatory event, being a result of sharing the same shelter, revealed the opportunistic predispositions of that generalist predator in a situation in which its typical prey was absent. This suggested that small amphibians may be a source of food for carabids, even for only moderately large species, in late autumn and winter shelters.

R. Bernard, Department of Nature Education and Conservation, Adam Mickiewicz University, Umultowska 89, PL-61-614 Poznań, Poland; E-mail: rbernard@amu.edu.pl

J. Samolag, Poznańska 72, PL-62-080 Tarnowo Podgórne, Poland; E-mail: samolag.juliusz@op.pl

Received 15 April 2014, accepted 18 August 2014

\section{Introduction}

Predation on vertebrates by invertebrates is much less common than the opposite situation, but it is also widespread, especially in arachnids and insects (McCormick \& Polis 1982). In the latter taxon, this is common in water bodies where representatives of five orders hunt on tadpoles and small fish, and relatively uncommon in terrestrial ecosystems where it is mainly recorded in ants and marginally in Mantodea and two families of Coleoptera, Carabidae and Cicindellidae (McCormick \& Polis 1982, Toledo 2005). The aim of this paper is to document predation on a caudate amphibian by a carabid beetle in natural but specific conditions of winter shelters.

\section{Material and methods}

An observation was made in the fortifications built in the 1930s SE of the village of Strzaliny, NW Poland, 5311'09" N 16¹3'11" E. Their aboveground parts have largely been destroyed whereas a $540 \mathrm{~m}$ long section, situated deep below the surface, is fairly well preserved and characterised by total darkness and quite stable winter microclimatic conditions, with temperatures of $3-9.6{ }^{\circ} \mathrm{C}$ and humidity of $69-98 \%$ in various sites. The surface ruins and underground corridors are connected by a narrow staircase.

During February censuses of hibernating bats in 1989-2014 (e.g. Bernard \& Samolag 2002) other animals wintering in the underground corri- 


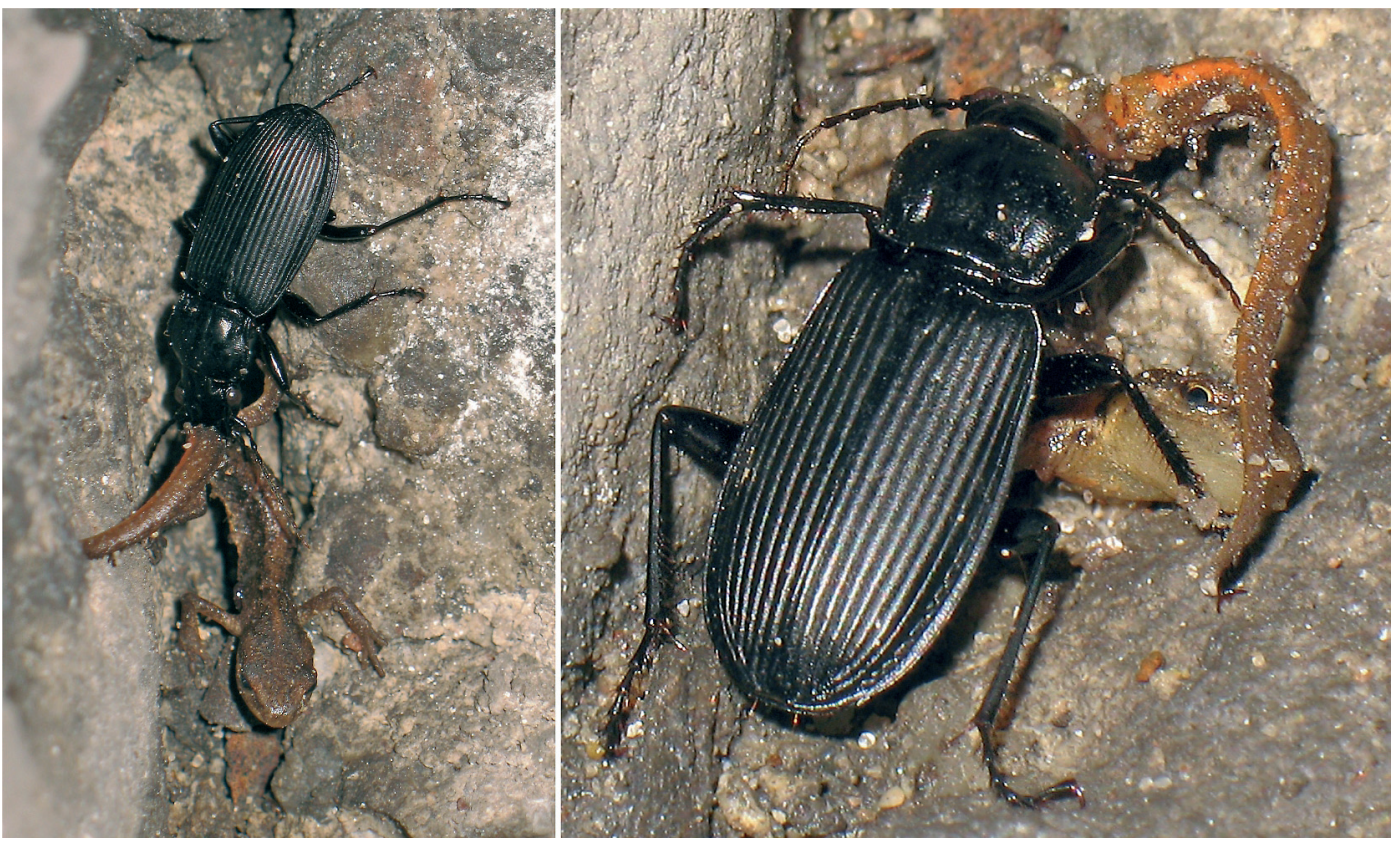

Fig. 1. Pterostichus niger (Schaller) preying on overwintering Lissotriton vulgaris (Linnaeus) in the underground fortifications near Strzaliny, North-Western Poland. Two observed phases of the predatory event. Photographed by J. Samolag.

dors, i.e. insects, amphibians and mammals, were also recorded. The analysed predatory event was observed by torch light from a small distance of 0.3-1 $\mathrm{m}$ between 13:26 and 15:51 (CET) with some breaks and it was documented on photographs. Temperature and humidity were measured with the use of data loggers near the observed animals.

\section{Results}

On 4 February 2014 one small (some $25-30 \mathrm{~mm}$ ) and slender individual of the Smooth Newt, Lissotriton vulgaris (Linnaeus), kept by some 16-19 mm long carabid beetle, Pterostichus niger (Schaller), was found in a shallow niche at the outer edge of a crack in a thick concrete wall (Fig. 1). This deep (0.45-0.85 $\mathrm{m}$ ) and narrow (7$11 \mathrm{~mm}$ ) crevice is situated some $11 \mathrm{~m}$ below the earth's surface, in a narrow transition connecting a staircase and underground corridors. Though close to the cool staircase, this transitional section is characterised by fairly stable winter temperatures and humidity, some $7{ }^{\circ} \mathrm{C}$ and $80 \%$, respectively.

At first $P$. niger bit and kept the rear part of the prey body just behind its hind legs (Fig. 1). The newt was mostly immobile making only tail movements. During the second phase of the observation, almost two hours later, the beetle was already situated above the newt's turned and partly lying body though the original grip was still not loosened (Fig. 1). Then the consumption of the newt's thoracic part began and was still continued when we had to finish the observation and most of the newt's body was still not eaten. The predatory event was observed for two hours and twenty five minutes but it must have taken longer both before and after the observation.

\section{Discussion}

The predatory event of this study was observed in the crevice where wintering amphibians had been detected at various depths over several winters thus showing its favourable microclimatic conditions, being more sheltered and humid than those outside the crevice. Three to nine individuals of L. vulgaris have wintered there regularly in the last three years while other species were sporadic during February censuses: Triturus cristatus 
(Laurenti) - one in 2007, Bombina bombina (Linnaeus) - one in 2012 and Rana sp. - two in 2011.

Predation on amphibians by carabid beetles, mostly by adults but also by larvae, is a rare phenomenon known in nature only for some species (Toledo 2005, Toshiaki 2006, Elron et al. 2007, Wizen \& Gasith 2011a, 2011b). It has mostly been observed in the genus Epomis whose three representatives as well as one related species of Chlaenius may even be temporarily specialized to some extent in this vertebrate prey, especially in small anuran metamorphs (Robertson 1989, Toledo 2005, Toshiaki 2006, Elron et al. 2007, Wizen \& Gasith 2011a, 2011b). Caudate amphibians, such as small salamanders and newts, were recorded as carabid prey much more rarely and only in the laboratory experiments (Ovaska \& Smith 1988, Wizen \& Gasith 2011a). In the genus Pterostichus, predation on amphibians has been recorded only in induced conditions in a laboratory. However, Pterostichus melanarius (Illiger), a relative of $P$. niger, was assessed in these experiments as less morphologically and behaviourally suited than Scaphinotus angusticollis (Mannerheim) to prey on juvenile salamanders (Ovaska \& Smith 1988). Therefore, it was not clear to what extent its predation on amphibians was only a result of that induced situation.

The present first record of $P$. niger preying on a newt confirms the occurrence of predation on small caudate amphibians by carabid beetles in natural conditions. It also suggests that the representation of carabids preying on amphibians may be wider than previously thought and may concern species sharing shelters with small caudates in late autumn to early spring. This phenomenon does not seem to be restricted to the largest beetles. Pterostichus niger and some other carabids known for predation on amphibians, $P$. melanarius and Chlaenius darlingensis Castelnau, are at most moderately large with a body size of between 15 and $20 \mathrm{~mm}$.

Pterostichus niger is a eurytopic but silvicolous generalist predator frequently feeding on insect larvae and slugs (Lindroth 1986, Port et al. 2000). The captured newt, considering its delicate build and small size, being some 1.5 as large as that of $P$. niger, did not differ essentially from the typical prey of that beetle. What is more, the newt must have been barely active, so it was eas- ily accessible in these low temperatures. Considering these circumstances, the small newt seems to be rather an occasional than a regular diet component of $P$. niger. Feeding on it appears to be a consequence of the common wintering locality shared by the less active potential prey and the opportunistic predator in a situation in which its typical prey items were absent.

Since the observed predatory event took place neither in water nor near water bodies and neither in the amphibian breeding season nor when metamorphs emerged, it substantially differs, both spatially and temporally, from most frequently recorded predation on amphibians by invertebrates (see Toledo 2005). Some winter activity has been recorded in 73 carabid species in Central and Northern Europe so far, but in $P$. $n i-$ ger this was previously known only from the beginning of April, i.e. the very end of the winter season (Jaskuła \& Soszyńska-Maj 2011).

It seems that $P$. niger as a generalist predator did not direct its attack at a specific part of the newt, as it was earlier shown in its predation on slugs (Port et al. 2000). On the contrary, specialized species of Epomis which prey on amphibians, usually directed attacks on a specific part of their body, in anurans on the lower back area or rear limbs and in Triturus vittatus (Gray) at the central venter (Wizen \& Gasith 2011a), to immobilise the prey quickly. However, the direction of the attack of $P$. niger in Strzaliny might also have been unfocused due to the complete darkness.

The long duration of the still unfinished predatory event might have been related to the low ambient temperature. However, Port et al. (2000) suggested that it is typical that attacks not directed at a specific part of a slug lead to extended handling times.

Acknowledgements. We are grateful to Dr. Paweł Sienkiewicz for help in the determination of the carabid species and to an anonymous reviewer for the comments and suggestions which helped us to improve the manuscript.

\section{References}

Bernard, R. \& Samolag, J. 2002: Bat censuses 1993-1999 in Strzaliny (North-Western Poland). - Nietoperze 3: 17-25. [In Polish with an English summary.]

Elron, E., Shlagman, A. \& Gasith, A. 2007: First detailed 
report of predation on anuran metamorphs by terrestrial beetle larvae. - Herpetological Review 38: 30-33.

Jaskuła, R. \& Soszyńska-Maj, A. 2011: What do we know about winter active ground beetles (Coleoptera, Carabidae) in Central and Northern Europe? - ZooKeys 100: 517-532.

Lindroth, C. H. 1986: The Carabidae (Coleoptera) of Fennoscandia and Denmark. - Fauna Entomologica Scandinavica 15, part 2: 1-497.

McCormick, S. \& Polis, G. A. 1982: Invertebrates that prey on vertebrates. - Biological Review 57:29-58.

Ovaska, K. \& Smith, M. A. 1988: Predatory behavior of two species of ground beetles (Coleoptera: Carabidae) towards juvenile salamanders (Plethodon vehiculum). - Canadian Journal of Zoology 66: 599-604.

Port, G. R., Glen, D. M. \& Symondson, W. O. C. 2000: Success in biological control of terrestrial molluscs. In: Gurr, G. \& Wratten, S. (eds.), Biological control: measures of success: 133-157. Kluwer Academic Publishers, Dordrecht. 429 pp.

Robertson, J. G. M. 1989: Predation by a carabid beetle on Australian frogs. - Herpetological Review 20: 7-8.

Toledo, L. F. 2005: Predation of juvenile and adult anurans by invertebrates: Current knowledge and perspectives. - Herpetological Review 36: 395-400.

Toshiaki, H. 2006: Predation by a carabid beetle (Epomis nigricans) on a juvenile frog (Rana nigromaculata). - Bulletin of the Herpetological Society of Japan 2006(2): 99-100.

Wizen, G. \& Gasith, A. 2011a: Predation of amphibians by carabid beetles of the genus Epomis found in the central coastal plain of Israel. - ZooKeys 100: 181-191.

Wizen, G. \& Gasith, A. 2011b: An unprecedented role reversal: ground beetle larvae (Coleoptera: Carabidae) lure amphibians and prey upon them. - PLoS ONE 6(9): e25161. 